\title{
Evaluation of peritoneal tissue by means of differential scanning calorimetry (DSC)
}

\author{
Kamil Torres ${ }^{1,2}$, Hanna Trębacz ${ }^{3}$, Andrzej Chrościcki², Łukasz Pietrzyk ${ }^{1}$, Anna Torres ${ }^{1}$ \\ ${ }^{1}$ Department of Human Anatomy, Laboratory of Biostructure, Medical University of Lublin, Poland \\ ${ }^{2}$ General Surgery Department of the District Specialist Hospital, Lublin, Poland \\ ${ }^{3}$ Department of Biophysics, Medical University of Lublin, Poland
}

\begin{abstract}
Abdominal surgeries alter the integrity of the peritoneal layer and cause imbalances among immunological, inflammatory and angiogenic mechanisms within the tissue. During laparoscopic procedures a protective function of the peritoneal layer can be disturbed by the gas used to create a pneumoperitoneum. The aim of this study was to characterize peritoneal tissue by means of differential scanning calorimetry (DSC) as a reference for future investigations on the influence of surgical procedures on the physicochemical state of the peritoneum. Thirty-seven patients participated in the study. Patients were divided into three groups according to the type of surgery: group $\mathrm{H}$ - patients who underwent hernia repair; group $\mathrm{Ch}$ - patients who underwent laparoscopic cholecystectomy; and group $\mathrm{C}$ - patients operated due to rectal cancer. It was observed that onset temperature $\left(\mathrm{T}_{\mathrm{o}}\right)$, denaturation temperature $\left(\mathrm{T}_{\mathrm{m}}\right)$ and change of enthalpy $(\Delta \mathrm{H})$ during thermal denaturation of peritoneal collagen in were significantly different for these three groups of patients. The mean values of onset temperature $\left(\mathrm{T}_{\mathrm{o}}\right)$ and denaturation temperature $\left(\mathrm{T}_{\mathrm{m}}\right)$ in group $\mathrm{H}$ were significantly lower, while $\Delta \mathrm{H}$ in this group was significantly higher than in the two other groups (Ch and $\mathrm{C}$ ). This preliminary study does not answer whether the differences in collagen denaturation found in peritoneal tissue from different groups of patients resulted from a different inherent state of the tissue, or from surgical procedures. However, the results suggest that DSC is an appropriate method to study subtle changes in the physicochemical condition of the peritoneum using small samples obtained during surgical procedures. (Folia Histochemica et Cytobiologica 2011; Vol. 49, No. 4, pp. 700-705)
\end{abstract}

Key words: differential scanning calorimetry, peritoneum, pneumoperitoneum, collagen, laparoscopy

\section{Introduction}

Abdominal surgeries alter the integrity of the peritoneal layer and cause imbalances among immunological, inflammatory and angiogenic mechanisms within the tissue.

Laparoscopic surgery has become standard in the treatment of cholelithiasis. Laparoscopic cholecystectomy is one of the most frequently performed procedures in the surgical wards. Better cosmetic effect,

Correspondence address: K. Torres, Department of Human Anatomy, Laboratory of Biostructure, Medical University of Lublin, Jaczewskiego Str. 4, 20-090 Lublin, Poland; e-mail:kamiltorres@wp.pl shorter hospitalization time and higher quality of life are well proven advantages of this surgical technique. However, laparoscopic surgery is not devoid of disadvantages which in part are related to the influence of carbon dioxide used for the creation of a pneumoperitoneum. The protective function of the peritoneum can be disturbed by the physical as well as the chemical action of the gas used to create a pneumoperitoneum. As a result, immunological, inflammatory and angiogenic imbalances occur [1].

The peritoneum consists of mesothelial cells entrapped in a network of connective tissue and directly adherent to the basal lamina (matrix) which consists of collagen, glycoproteins, proteoglycans and glycosaminoglycans. Such a network of lymphatic, venous and arterial vessels localized within the basal mem- 
brane can become compressed during a pneumoperitoneum, resulting in disturbances to the local bloodflow. Apart from mechanical injury, the gases used for the creation of a pneumoperitoneum may influence the integrity, humidity and temperature of the peritoneal layer. Drying of the peritoneal epithelium under the influence of carbon dioxide pneumoperitoneum results in gaps in the normal thigh intercellular junctions which leads to gradual peritoneal cells detachments from the basal lamina. Such mesothelial cells secrete inflammatory mediators (IL-6, IL-8, TNF- $\alpha$ ) intracellular adhesion molecules and fibrynolitic reaction mediators [2-7].

Collagen is the major structural protein present in the peritoneum. In its native form, the collagen molecule has a triple helical structure held together by hydrogen bonds. During thermal denaturation, these hydrogen bonds break, and the helices unfold and form coils. Thermally induced transformations of collagen reflect the overall condition of the structure, cross-links in the collagen network and interactions with the surrounding molecules [8-10]. Differential scanning calorimetry (DSC) provides a powerful method for examining conditions in which the stabilization of protein breaks down, and has been proved to be sensitive to the amount of cross-links as well as to the hydration and the molecular environment of the collagen molecules [10-15].

While generally the heat-induced denaturation of proteins is reasonably well understood, the heat denaturation of structural proteins within whole tissues remains an area of active research. DSC studies have proved to be valuable in assessing the role of collagen in structural alterations of aortic walls in abdominal aortic aneurysms and in mechanical alterations associated with mitral valve dysfunctions, as well as in the characterization of aortic tissues for cardiac valve bioprostheses and artificial blood vessels [16-19]. The calorimetric method has been successfully applied in investigations of collagen in mineralized bone tissue $[11,15,20]$. DSC data has also been shown to be sensitive to native and artificially induced intermolecular cross-links in collagen in cornea and lens capsules, and in degenerative disc disease $[21,22]$.

The aim of this study was to characterize peritoneal tissue by means of differential scanning calorimetry (DSC) as a reference for future investigations on the influence of surgical procedures on the physicochemical state of the peritoneum.

\section{Material and methods}

This study was conducted in tissue specimens obtained from 37 patients admitted to the Department of General and
Oncological Surgery of the District Specialist Hospital in Lublin, Poland between January and March 2010. All patients were scheduled for surgery. Patients were divided into three groups according to the type of surgery. The first group (H) consisted of patients who underwent hernia repair (13 patients, six females, seven males); the second $(\mathrm{Ch})$ was composed of patients operated due to cholelithiasis (14 patients, 12 females, two males) using laparoscopic method; while the third group (C) consisted of ten patients, (five females, five males) operated due to rectal cancer. Additionally, patients were assigned to two subgroups according to BMI values. Subgroup A consisted of patients with BMI values less than $30 \mathrm{~kg} / \mathrm{m}^{2}$ while subgroup B consisted of patients with BMI equal to or above $30 \mathrm{~kg} / \mathrm{m}^{2}$. There were 15 patients with BMI $\geq 30 \mathrm{~kg} / \mathrm{m}^{2}$, six in group $\mathrm{H}$, five in group $\mathrm{Ch}$ and four in group $\mathrm{C}$.

All patients included in the study were informed about the aims of the research and written consent was obtained from each patient. The study design was approved by the Medical University of Lublin ethical committee.

One sample of peritoneal tissue $\left(1.0-1.5 \mathrm{~cm}^{2}\right)$ was collected from each patient during the surgical procedure. Samples were immersed in $0.9 \% \mathrm{NaCl}$ and cooled to $4^{\circ} \mathrm{C}$. Within two days of surgery, differential scanning calorimetry was performed using a Q200 (TA) calorimeter. 8-10 mg samples of peritoneum with $10 \mathrm{ml}$ of saline were sealed in hermetic aluminium pans and scanned from $40^{\circ} \mathrm{C}$ to $85^{\circ} \mathrm{C}$ at heating rate $5^{\circ} \mathrm{C} / \mathrm{min}$. A reference pan filled with pure $0.9 \%$ $\mathrm{NaCl}$ solution was scanned in parallel for each sample. The initial temperature of transition (the onset temperature, $\mathrm{T}_{\mathrm{o}}$ ), the peak temperature $\left(\mathrm{T}_{\mathrm{m}}\right)$, the temperature of protein denaturation and the energy absorbed by the sample during transition were determined from thermograms (Figure 1). Change of enthalpy $(\Delta \mathrm{H})$ during the process was expressed as energy of transition for one gram of dry mass of the sample. Dry mass of the sample was measured following calorimetry and 24 hours drying at room temperature in an exsicator.

Data was analyzed using SPSS v.16 software. ANOVA test with Tuckey's post-hoc analysis was used to investigate differences between three groups of patients. Differences between the two BMI subgroups in each group were tested using Student's $t$-test. In both tests, differences were considered significant if $\mathrm{p}<0.05$.

\section{Results}

In all peritoneal tissue samples, a non-reversible endothermic process with maximum at temperatures between $65.20^{\circ} \mathrm{C}$ and $70.0^{\circ} \mathrm{C}$ and enthalpy change from $4.0 \mathrm{~J} / \mathrm{g}$ to $31.5 \mathrm{~J} / \mathrm{g}$ was observed. Median values of DSC parameters of peritoneum in three groups of patients are shown in Figures 2 and 3. Values of the onset temperature $\left(\mathrm{T}_{\mathrm{o}}\right)$ and the peak temperature $\left(\mathrm{T}_{\mathrm{m}}\right)$ in group $\mathrm{H}$ were lower than in the other two groups, 


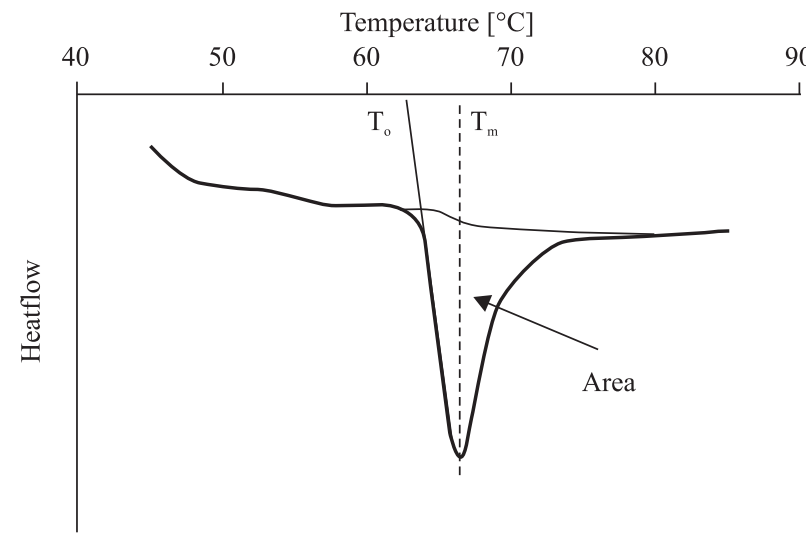

Figure 1. A typical DSC thermogram for a peritoneal sample. The curve represents a transition from a native to denaturated state of the sample. $T_{0}$ - initial temperature of the transition, $T_{m}$ (peak temperature) - temperature of denaturation, the area of the peak is equal to the energy absorbed by the sample during transition

while change of enthalpy $(\Delta \mathrm{H})$ was higher than in the other two groups.

Significant differences between the three groups were observed for each of the calorimetric parameters measured in peritoneal samples (Table 1). Specifically, the post-hoc tests revealed differences between group $\mathrm{H}$ and group $\mathrm{Ch}(\mathrm{p}<0.0001$ for each calorimetric parameter) and between groups $\mathrm{H}$ and $\mathrm{C}\left(\mathrm{p}=0.001\right.$ for $\mathrm{T}_{\mathrm{o}}, \mathrm{p}=0.008$ for $\mathrm{T}_{\mathrm{m}}$ and $\mathrm{p}=0.004$ for $\Delta \mathrm{H})$. Differences between groups $C h$ and $\mathrm{C}$ were not statistically significant. Enthalpy and $T_{m}$ in two $\mathrm{C}$ samples were not included in the statistics, as the samples did not return to a new equilibrium state after denaturation and collapsed before the denaturation process was completed.

No significant differences were encountered when two BMI subgroups were compared.

Additionally, in the patients who underwent cholecystectomy (group $\mathrm{Ch}$ ), the presence of adhesions was examined as well as their possible influence on the calorimetric parameters of the peritoneum. However, we did not observe any statistically significant difference between subgroups with and without adhesions for any of analyzed parameters.

\section{Discussion}

In this study, DSC investigations of the physical state of the peritoneum were performed in peritoneal samples from patients undergoing three different types of surgical procedure. In all samples, a non-reversible endothermic process starting above $60^{\circ} \mathrm{C}$ was recorded. Considering that collagen is a main structural protein of the peritoneum, we attribute the ther-

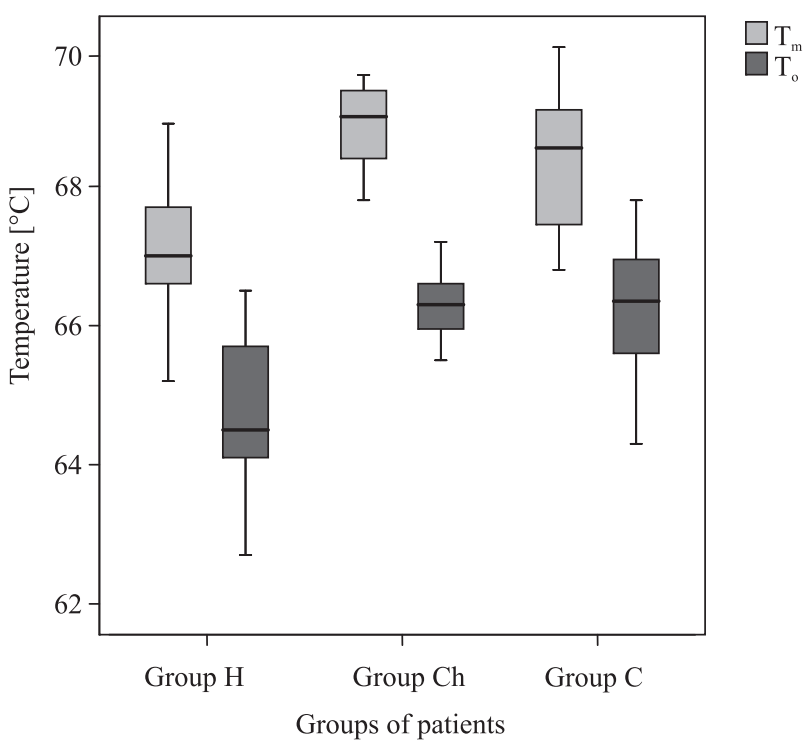

Figure 2. Medians of the onset temperature $\left(\mathrm{T}_{\mathrm{o}}\right)$ and the denaturation temperature $\left(\mathrm{T}_{\mathrm{m}}\right)$ of peritoneal samples in the three studied groups $(\mathrm{H}$ - hernia group, $\mathrm{Ch}$ - laparoscopic cholecystectomy group, and $\mathrm{C}$ - cancer group)

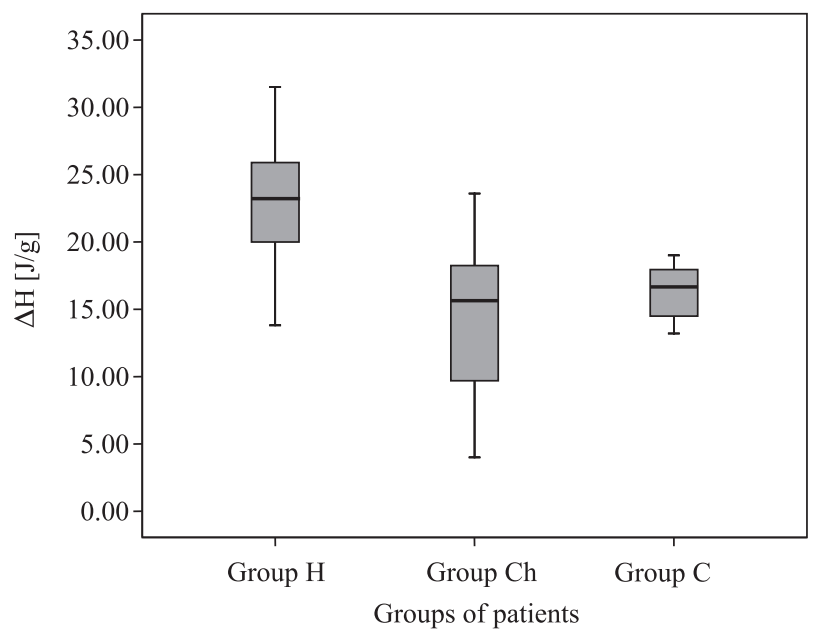

Figure 3. Change of enthalpy $(\Delta \mathrm{H})$ in three studied groups ( $\mathrm{H}$ - hernia group, $\mathrm{Ch}$ - laparoscopic cholecystectomy group, and $\mathrm{C}-$ cancer group)

mal activity of the sample to denaturation of collagen molecules. The process of thermal activation of type I collagen involves rupture of hydrogen bonds coupling the three $\alpha$-chains and a rearrangement of the triple helix into a random chain configuration $[8,9]$. In most of our samples, the denaturation endotherm was followed by an equilibrium state adequate to the new configuration of the protein molecules at temperatures just above $70^{\circ} \mathrm{C}$. Similar values of denaturation temperatures have been reported for samples from other collagen-based tissues [12-14, 16-18, 21]. 
Table 1. Results of statistical analysis of DSC parameters of peritoneum samples in three groups of patients: $\mathrm{H}-$ hernia; $\mathrm{Ch}$ - cholelithiasis; $\mathrm{C}$ - rectal cancer

\begin{tabular}{|c|c|c|c|c|c|c|}
\hline & & $\mathbf{n}$ & Mean & Std. dev. & Minimum & Maximum \\
\hline \multirow[t]{4}{*}{$\mathrm{T}_{\mathrm{o}}$} & $\mathrm{H}$ & 13 & 64.69 & 1.12 & 62.7 & 66.5 \\
\hline & $\mathrm{Ch}$ & 14 & 66.33 & 0.52 & 65.5 & 67.2 \\
\hline & $\mathrm{C}$ & 9 & 66.31 & 1.03 & 64.3 & 67.8 \\
\hline & Total & 36 & 65.73 & 1.19 & 62.7 & 67.8 \\
\hline \multicolumn{2}{|c|}{ ANOVA, $p$} & \multicolumn{5}{|c|}{$<0.0001$} \\
\hline \multirow[t]{4}{*}{$\mathrm{T}_{\mathrm{m}}$} & $\mathrm{H}$ & 13 & 67.08 & 1.01 & 65.2 & 68.9 \\
\hline & $\mathrm{Ch}$ & 14 & 68.94 & 0.61 & 67.8 & 69.6 \\
\hline & $\mathrm{C}$ & 8 & 68.38 & 1.11 & 66.8 & 70.0 \\
\hline & Total & 35 & 68.12 & 1.21 & 65.2 & 70.0 \\
\hline \multicolumn{2}{|c|}{ ANOVA, $p$} & \multicolumn{5}{|c|}{$<0.0001$} \\
\hline \multirow[t]{4}{*}{$\Delta \mathrm{H}$} & $\mathrm{H}$ & 13 & 23.24 & 4.91 & 13.8 & 31.5 \\
\hline & $\mathrm{Ch}$ & 14 & 13.65 & 5.50 & 4.0 & 22.9 \\
\hline & $\mathrm{C}$ & 8 & 15.21 & 4.76 & 4.3 & 19 \\
\hline & Total & 35 & 17.67 & 6.68 & 4.0 & 31.5 \\
\hline \multicolumn{2}{|c|}{ ANOVA, $p$} & \multicolumn{5}{|c|}{$<0.0001$} \\
\hline
\end{tabular}

Std. dev. — standard deviation

Both the onset temperature and the peak temperature of the endotherm which reflect uncoupling of the collagen triple helix were significantly lower in the samples from patients with hernia (group $\mathrm{H}$ ) than in the two other groups. A possible reason for the observed difference could be a lower physical stability of collagen molecules in the peritoneum of the patients belonging to group $\mathrm{H}$. This might be one of the factors that facilitate the occurrence of hernia. It has been proven previously that in patients affected by hernia the changes of tissue collagen are related to the occurrence of this disease [23]. Moreover, the study by Klinge et al. revealed marked changes in the abundance and composition of interstitial collagens in patients with adult groin hernia and incisional hernia [24].

Stability of collagen molecules reflects the overall condition of the structure, cross-links in the collagen network and interactions with the surrounding molecules. Post-translational cross-links in collagen regulated by cellular activities and tissue turnover rate affect the size and physical properties of collagen fibers and consequently collagen-based tissues $[8,11,25]$. In a recent work performed in bariatric skin samples [26], higher enthalpy values and decreased onset temperature in DSC measurements were found in skin areas with histologically proven damage to the extracellular matrix as compared with normal skin samples.

On the other hand, DSC results have been proven to be very sensitive to the level of hydration of col- lagen. A considerable increase of the temperature of the helix-coil transition was found in dehydrated collagen fibers. Enthalpy of the denaturation process was also hydration-dependent, decreasing along with gradual dehydration of collagen $[10,15]$. An increase in the thermal stability was attributed to the reduced free-volume available for denaturing $\alpha$-chains in dehydrated collagen fibers in the presence of thermally stable cross-linking in and between collagen molecules in tissues [10]. Hence, the high temperatures of helix-coil transition together with low enthalpy values in groups $\mathrm{Ch}$ and $\mathrm{C}$ could result from disturbed water environment in these peritoneal samples.

Our study did not reveal any significant difference between groups $\mathrm{Ch}$ and $\mathrm{C}$ with regard to analyzed calorimetric parameters. However, an interesting difference between three groups was observed at temperatures above the denaturation process. In all samples belonging to groups $\mathrm{Ch}$ and $\mathrm{H}$, the denaturation endotherm was followed by a new equilibrium state for a new configuration of the molecules stable up to $85^{\circ} \mathrm{C}$. In half of the peritoneum samples from patients with tumors (C group), the new equilibrium state was not achieved and the samples disintegrated and collapsed at just above $70^{\circ} \mathrm{C}$. Additionally, disintegration, which started below $70^{\circ} \mathrm{C}$, was observed in two cancer samples. Therefore these samples were not included in the statistics.

Another interesting aspect of the results presented in this study is related to the laparoscopic proce- 
dure performed in patients with cholelithiasis. During laparoscopic surgery, the peritoneal integrity is altered due to the influence of physical injury and the action of carbon dioxide used for induction of a pneumoperitoneum. The modulation of the immunological system as well as the inflammatory reaction has been described by many authors [1].

Regardless of the shorter hospital stay and better cosmetic effect for the patients who undergo laparoscopic surgery, this technique is not immune from the consequences of surgical trauma [27-29]. Laparoscopic techniques have been continuously improved. $\mathrm{Nu}$ merous modifications minimizing the surgery-related trauma (i.e. SILS, Single Incision Laparoscopic Surgery) as well as the negative effects caused by the pneumoperitoneum have been introduced (i.e. low-pressure carbon dioxide pneumoperitoneum technique, gasless laparoscopy) [30-32].

Laparoscopic surgery affects the peritoneal layer that covers the abdominal cavity by physical damage (incisions) as well as in a chemical manner (carbon dioxide pneumoperitoneum). The single layer of mesothelial cells inserted in the connective tissue network and based on a connective tissue layer form the peritoneal membrane which is a crucial organ responding to the surgical trauma and inducing inflammatory, fibrynolitic, angiogenic as well as immunological reactions $[1,33,34]$. The peritoneal layer has a pivotal function in the process of wound healing. The induction of the angiogenic and fibrynolitic reactions will influence not only the wound healing but also the formation of adhesions [35, 36].

The peritoneal layer of the abdomen is a complicated structure made up of cubic mesothelial cells, a network of connective tissue, and the basal lamina composed of fibroblasts, collagen fibers and mast cells. It is essential for homeostatic maintenance to provide the peritoneal integrity, which can be affected during laparoscopic surgery, where mesothelial cells detach from the basal membrane and expose the basal membrane $[1,37,38]$. Several studies based on an animal model have showed that the bulging up of mesothelial cells occurs almost immediately after the initiation of a pneumoperitoneum. Additionally the gas pressure, type of gas and duration of insufflations used during laparoscopic surgery evokes changes to the integrity of the peritoneal layer [39,40]. The study performed by Fu et al. evaluated the peritoneal morphology of patients undergoing laparoscopic surgery. The authors revealed that areas without mesothelium, just with the basal connective tissue, can be found in the peritoneal layer 30 minutes after the beginning of the surgery, which is different to open abdominal surgeries $[1,41]$.
Other authors have proved that the flow of carbon dioxide used during laparoscopic surgery causes peritoneal layer damage. Direct damage of mesothelial cells occurs when dry gas flow lasts even $30 \mathrm{sec}-$ onds, and indirect collateral peritoneal damage after eight minutes of gas flow. The humid environment of the peritoneal layer is dried by the gas used for the creation of a carbon dioxide pneumoperitoneum. These conditions promote evaporation, and in effect dryness and damage of peritoneal cells [2,3]. Taking into account the extreme sensitivity of collagen molecules to the water environment, the physicochemical processes that occur in the tissue as a result of laparoscopy could explain the higher thermal stability and lower enthalpy of denaturation for samples obtained during cholecystectomy compared to the hernia group.

In summary, the differences observed in the denaturation process of the peritoneal tissue collagen could result from the different inherent state of the tissue characteristic for the surgical trauma. However, this study is a preliminary report and is insufficient to answer which of the possible causes contributes more to the obtained results. However, it was the first attempt to characterize the peritonuem by means of DSC. The results showed that this method could be appropriate for the study of subtle changes in the physicochemical condition of the peritoneum using small samples obtained during surgical procedures.

\section{References}

1. Brokelman WJ, Lensvelt M, Borel Rinkes IH et al. Peritoneal changes due to laparoscopic surgery. Surg Endosc. 2011;25:1-9.

2. Ott DE. The peritoneum and the pneumoperitoneum: a review to improve clinical outcome. Gynecol Surg. 2004;1: 101-106.

3. Ott D, Garner R, Wright E. Unmodified carbon dioxide gas used during laparoscopy results in loss of peritoneal cell viability. JSLS. 2000;4:347.

4. Ryan GB, Grobéty J, Majno G. Mesothelial injury and recovery. Am J Pathol. 1973;71:93-112.

5. Hamza MA, Schneider BE, White PF et al. Heated and humidified insufflation during laparoscopic gastric bypass surgery: effect on temperature, postoperative pain, and recovery outcomes. J Laparoendosc Adv Surg Tech A. 2005;15:6-12.

6. Bachus KE, Doty E, Haney AF et al. Differential effects of interleukin-1 alpha, tumor necrosis factor-alpha, indomethacin, hydrocortisone, and macrophage co-culture on the proliferation of human fibroblasts and peritoneal mesothelial cells. J Soc Gynecol Investig. 1995;2:636-642.

7. van Hinsbergh VW, Kooistra T, Scheffer MA et al. Characterization and fibrinolytic properties of human omental tissue mesothelial cells. Comparison with endothelial cells. Blood. 1990;75:1490-1497.

8. Bischof JC, He X. Thermal stability of proteins. Ann NY Acad Sci. 2005;1066:12-33. 
9. Bruylants G, Wouters J, Michaux C. Differential scanning calorimetry in life science: Thermodynamics, stability, molecular recognition and application in drug design. Curr Medicinal Chem. 2005,12:2011-2020.

10. Miles CA, Ghelashvili M. Polymer-in-a-box mechanism for the thermal stabilization of collagen molecules in fibres. Biophys J. 1999;76:3243-3252.

11. Knott L, Whitehead CC, Fleming RH et al. Biochemical changes in the collagenous matrix of osteoporotic avian bone. Biochem J. 1995;310:1045-1051.

12 Miles CA. Kinetics of collagen denaturation in mammalian lens capsules studied by differential scanning calorimetry. Int J Biol Macromol. 1993;15:265-271.

13. Nevzorov I, Redwood C, Levitsky D. Stability of two betatropomyosin isoforms: effects of mutation Arg91Gly.J Muscle Res Cell Moti. 2008;29:173-176.

14. Samouillan V, Dandurand J, Lacabanne C et al. Comparison of chemical treatments on the chain dynamics and thermal stability of bovine pericardium collagen. J Biomed Mater Res A. 2003,64:330-338.

15. Trębacz H, Wójtowicz K. Thermal stabilization of collagen molecules in bone tissue. Int J Biol Macromol. 2005;37: 257-262.

16. Samouillan V, Dandurand J, Lacabanne C et al. Characterization of aneurysmal aortas by biochemical, thermal, and dielectric techniques. J Biomed Mater Res A. 2010;95: 611-619.

17. Hadian M, Corcoran BM, Bradshaw JP. Molecular changes in fibrillar collagen in myxomatous mitral valve disease. Cardiovasc Pathol. 2010;19:e141-e148.

18. Samouillan V, Dandurand-Lods J, Lamure A et al. Thermal analysis characterization of aortic tissues for cardiac valve bioprostheses. J Biomed Mater Res. 1999;S46:531-538.

19. Cheng ST, Chen ZF, Chen GQ. The expression of crosslinked elastin by rabbit blood vessel smooth muscle cells cultured in polyhydroxy-alkanoate scaffolds. Biomaterials. 2008:4187-4194.

20. Trębacz H, Wójtowicz K. Thermostability of bone tissue after immobilization induced osteopenia in a rat model. Folia Histochem Cytobiol. 2008;46:379-782.

21. Sionkowska A. Thermal stability of UV-irradiated collagen in bovine lens capsules and in bovine cornea. J Photochem Photobiol B. 2005;80:87-92.

22. Skrzyński S, Sionkowska A, Marciniak A. DSC study of collagen in disc disease. J Biophys. 2009;2009:819635.

23. Franz MG. The biology of hernia formation. Surg Clin North Am. 2008;88:1-15.

24. Klinge U, Binnebösel M, Mertens PR. Are collagens the culprits in the development of incisional and inguinal hernia disease? Hernia. 2006;10:472-477.
25. Bailey AJ. Molecular mechanisms of ageing in connective tissues. Mech Ageing Dev. 2001;122:735-755.

26. Light D, Arvanitis GM, Abramson D, Glasberg SB. Effect of weight loss after bariatric surgery on skin and the extracellular matrix. Plast Reconstr Surg. 2010;125:343-351.

27. Gutt CN, Oniu T, Schemmer P et al. Fewer adhesions induced by laparoscopic surgery? Surg Endosc. 2004;18: 898-906.

28. Berggren U, Gordh T, Grama D et al. Laparoscopic versus open cholecystectomy: hospitalization, sick leave, analgesia and trauma responses. Br J Surg. 1994;81:1362-1365.

29. Shamiyeh A, Wayand W. Current status of laparoscopic therapy of cholecystolithiasis and common bile duct stones. Dig Dis. 2005;23:119-126.

30. Torres K, Torres A, Staśkiewicz GJ et al. A comparative study of angiogenic and cytokine responses after laparoscopic cholecystectomy performed with standard- and low-pressure pneumoperitoneum. Surg Endosc. 2009;23:2117-2123.

31. Wróblewski TM, Piotrowicz S, Kotulski M et al. No-visiblescar cholecystectomy. Videosurgery and other miniinvasive techniques. 2010;5:158-160.

32. Michalik M, Frask A, Trybull A et al. Methods of treatment for gallbladder diseases. Videosurgery and other miniinvasive techniques 2009;4:121-125.

33. diZerega GS. Biochemical events in peritoneal tissue repair. Eur J Surg Suppl. 1997;577:10-16.

34 Chegini N. Peritoneal molecular environment, adhesion formation and clinical implication. Front Biosci. 2002;7:e91-e115.

35. Chegini $\mathrm{N}$. The role of growth factors in peritoneal healing: transforming growth factor beta (TGF-beta). Eur J Surg Suppl. 1997;577:17-23.

36. Chegini N. TGF-beta system: the principal profibrotic mediator of peritoneal adhesion formation. Semin Reprod Med. 2008;26:298-312.

37. Michailova K, Wassilev W, Wedel T. Scanning and transmission electron microscopic study of visceral and parietal peritoneal regions in the rat. Ann Anat. 1999;181:253-260.

38. Wassilev W, Wedel T, Michailova K et al. A scanning electron microscopy study of peritoneal stomata in different peritoneal regions. Ann Anat. 1998;180:137-143.

39. Suematsu T, Hirabayashi Y, Shiraishi N et al. Kitano morphology of the murine peritoneum after pneumoperitoneum vs laparotomy. Surg Endosc. 2001;15:954-958.

40. Volz J, Köster S, Spacek Z et al. Characteristic alterations of the peritoneum after carbon dioxide pneumoperitoneum. Surg Endosc. 1999;13:611-614.

41. Fu C, Li GY, Liu FY et al. Effect of carbon dioxide pneumoperitoneum-laparoscopic surgery on tumor seeding and metastases in endometrial cancer. Zhong Nan Da Xие Xиe Bao Yi Xue Ban. 2008;33:130-137. 